\title{
LONG-TERM INFRASTRUCTURE INVESTMENT: A NEW APPROACH TO THE ECONOMICS OF LOCATION
}

\author{
Petr Dlask, Václav Beran
}

\section{Introduction}

In both classical economics (Adam Smith, David Ricardo) and neoclassical economics (e.g. John Hicks, Léon Walras, William Stanley Jevons, George Stigler, Carl Menger, John Bates Clark), there are three primary factors of production: land, labor, capital. Land means a resource creating an additional utility and is not only a natural resource to be found above or below the soil. There cannot be a disregard for the decision making process concerning location and investment. The problem is manifest not only in the individual solo investment but also in the portfolio dispersion of investment in an entire region.

The article focuses on the arguments supporting the thesis (implication): the decision rule creates the decision space and this space (meant as an occasion for manoeuvre) if evaluated, provides the utility. Discrepancies in the assessment of development opportunities in a regional or urban area are well-known matters of discussion and have serious long term economic consequences. Let us consider the above statement as a goal-setting endeavour. The statement formulates the specific and measurable intentions, and the intent of the authors is to query whether goals are attainable, realistic and time-bound. More generally it describe a situation carrying the implication

Economic decision Rule $\Rightarrow{ }^{\text {create }}$ Economic decision Space $\Rightarrow$ evaluate Economic decision Utility

or adjusted to eliminate the redundant words

$$
\text { Rule } \Rightarrow{ }^{\text {reate }} \text { Space } \Rightarrow{ }^{\text {evaluate }} \text { Utility }
$$

It will not be amiss to look briefly for the causes of gaps in theory and/or in any application to actual practice. The factual gaps may be perceived in: a) a good evaluation of solo investment and b) the unsatisfactorily calculated impact of investment in an area (region). The evaluation methodology suffers from a) the absence of probabilistic causality, b) weak respect for the dynamics in time, c) disregard of the influence of decision-making rules, and d) marginalization of the effect of externalities (the dynamic of chain effects in the area, and the economic impact of location addressed in sub-section 2.2).

Motivation: The main reason for writing this article was the findings visualized in Fig. 1. The differentiated development is presented for Central and Eastern Europe. The findings and data illustrate an existing situation elaborated by the World Bank. The article searches for reserves in locating investments and any potential to increase productivity for the region (Artis, Curran, \& Sensier, 2010).

Implementation: The development of cities can be efficient, but it happens not always by design. Fixation on the distant target or vision has mostly a higher priority than dynamics and orientation in the process for achieving longterm goals. The inspirations behind, or rather some indicators of, the general problem is addressed by (Mandelbrot, 1991) and other authors and an extensive overview is presented by (Wolfram, 2002).

Application: An economic development including development of settlements, industries, regions, etc. depends on the presence of the necessary infrastructure as a condition for investment; but it is not a sufficient condition. According to radical changes sought in the EU (European Commission, 2013), the following must happen: greater accessibility and readiness for integration of data from the three principal sources (public, private and societal) taking matters beyond the Directive 2013/37/EU. 


\section{Literature - Synopsis and Comments}

Some authors sum up the problem mentioned in (European Commission, 2013) from different angles, and talk about the issue in terms of dynamics, risks, uncertainties, dimensions $(1 \mathrm{D}, 2 \mathrm{D}, \ldots$, etc.). The question of dynamics in the economy was made evident already in (Forrester, Industrial Dynamics, 1961) and also later (1969) in Urban Dynamics (Forrester, 1969). Comparison and evaluation of consequences in time is the main source of the discrepancy in any given situation. The theory of economics and management (E\&M) currently addresses the desire for further development in various ways. We have to mention at least Econophysics, and the related concerns addressed by (Gallegati, Keen, Lux, \& Ormerod, 2006) or sustainable development in (Stern, 2006). The main problems or difficulties are found in the following: dynamics of time, area structure, causal interaction of the action, action risk, uncertainty, prudence, ethical standards, etc. Investments and the active process of investing are widely recognized as a tool for economic development (Artis, Curran, \& Sensier, 2010), (Beran \& Dlask, 2005 ; 2011). The question poses enquiry around the respective conditions of necessity and sufficiency for any economic development. The article experiments with the hypothesis that instead of demanding generic models, the decision-making rules should create the backbone structure of most economic and managerial problems, see for example (Mitsova, Shuster, \& Wang, 2011), (Parker, 2007), (Prunetti, Muzy, \& Innocenti, 2014) and (Stanilov \& Batty, 2011). It is necessary to point out the limitations of any new solutions.
Limit 1: A lot of different types of knowledge and information may overshadow a hopeful endeavor, for example in (Malecki, 2012), regarding activities about an urban retrofitting in (Dixon, Eames, Hunt, \& Lannon, 2014). Mitroff \& Silvers describe this potential of overshadowing as Probabilistic causality in (Mitroff \& Silvers, 2013). The idea of the "multi-fiber" probabilistic causality is inspiring. The probabilistic conception of causality is an important and interesting problem. It is noteworthy that in most of the generic models the users generally deal only with a segment of the influencing parameters. Such an approach does not respect the parameter volatility for decision making (DM). Let us give a brief example in explanation.

For investment aims in (Stimson, Stough, \& Brian, 2006) states it is possible to construct a causality matrix (Mitroff \& Silvers, 2013), and the activities Infrastructure and NotInfrastructure play the role of the initiating condition while Investment and Not-Investment play the role of a responding activity. The matrix is presented in Tab.1.

The causal interactions $a_{i j}$ in the matrix in Tab. 1 shows possible outcomes of the implication Infrastructure $\Rightarrow$ Investment. Another approach presents process/product and qualitative/quantitative aspects as presented in (Lennert \& Robert, 2010). It is undeniable that the infrastructure plays the role of a necessary condition and the investment the condition of sufficiency. The outcome $a_{11}$ in Tab. 1 is commonly considered as appropriate for action permission. However the decision maker deserves more sensitive and specific information about topic "climate": as $a_{12}, a_{21}, a_{22}$. Most decision-making methods (Net present

\section{Tab. 1: Regional development and investment as a causal interaction (in an area $\omega$ )}

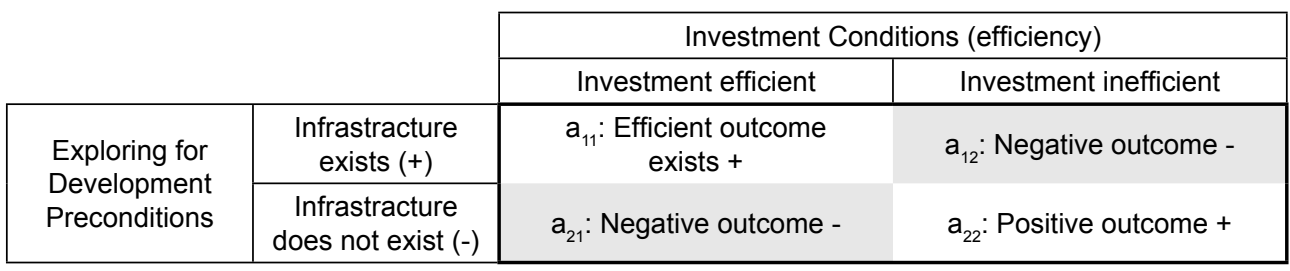


value NPV, Internal rate of return IRR, Pay-back period and others) are based on a deterministic causal nexus, which has only a limited validity in the real world.

Limit 2: The tendency to tackle only one single situation $a_{11}$ has in many situations a limited validity as well. The regional development (RD, settlements, cities, regions) is subject to some kind of causalities in 3D space with the segmented areas $X, Y, Z$ and their benefits or efficiency and utility as their fourth axis. The wording of the dimension is taken from ISO 16739:2013 where there is presented an extension to 4D-image (time) and 5D-image (costs).

\section{Fig. 1: Economic activity (GDP/km²) in Central Europe - an uneven topography}

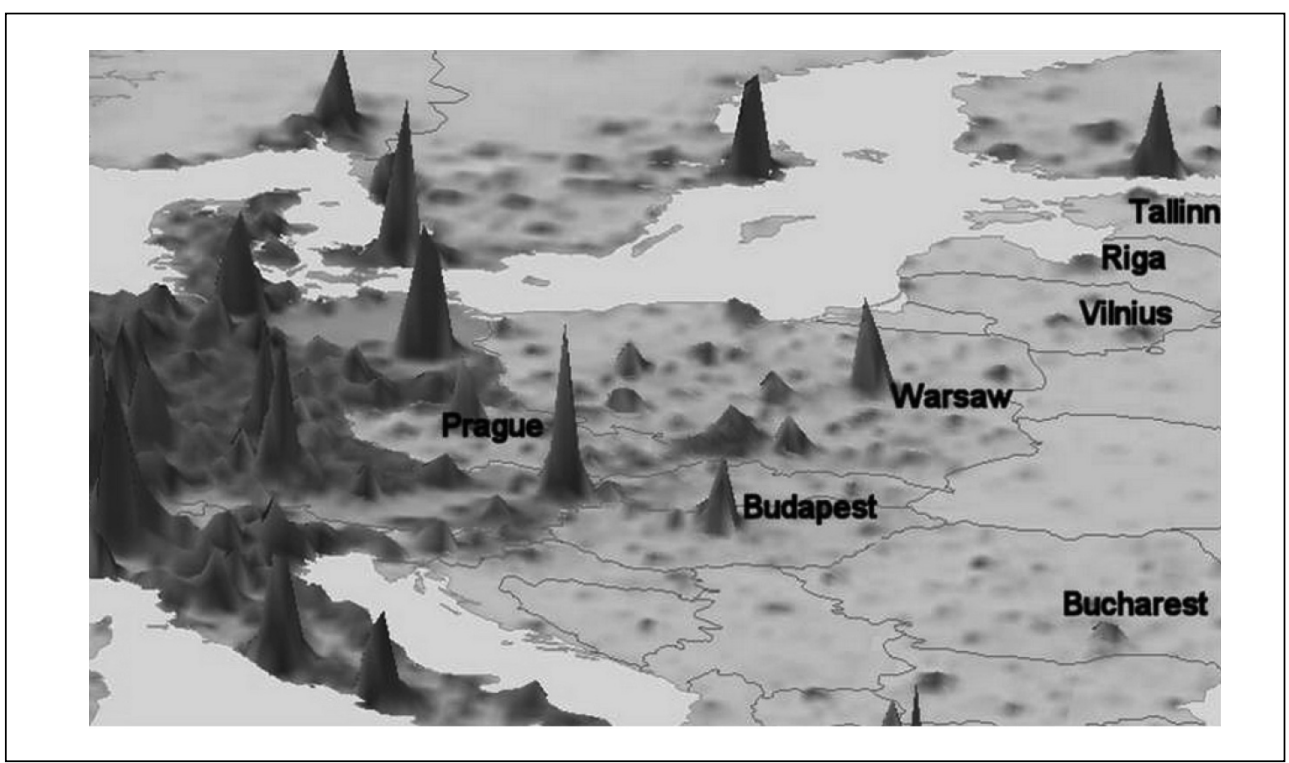

Source: World Bank GIS Laboratory

The analysis of a landscape and its texture, along with spatial analyses are the disciplines that open more insights into the behavior of regions (Tao, Tang, \& Strobl, 2012). Many authors are looking for an answer in simulation and in a spatial structures model as supporting tasks.

Limit 3: Development is a dynamic process in time (Artis, Curran, \& Sensier, 2010), (Beran \& Dlask, 2005; 2007; 2011), and in actuality an urban or investment arrangement takes place in space. The relevance of the topic urban development and cellular methodology and its rapid emergence in the last 15 years is evident from the data shown in database ISI. The published items about "urban development and cellular methodology" (per year) increases from nearly zero before year 2000 to more than 700 in 2013/2014.
Society and indeed almost every individual or citizen requires that the urban arrangement, the regional infrastructure and its economy can provide high benefits in time and space.

Limit 4: Dysfunctional practice is rooted in defective theory. Decision rules are underestimated in management practice. A rule shows the way - direction - for the construction of roads, railways, waterways, public buildings, residential buildings, and their architectural arrangement; rules express the use of a public or private space - and this has been so for centuries. They were developed by means of a consensus in the rules of DM for the creation of the arrangement of a whole space development, as well as the economic and cultural background to it (the technical-economic memory of the given space). A formalization of DM rules decreases apprehension regarding 

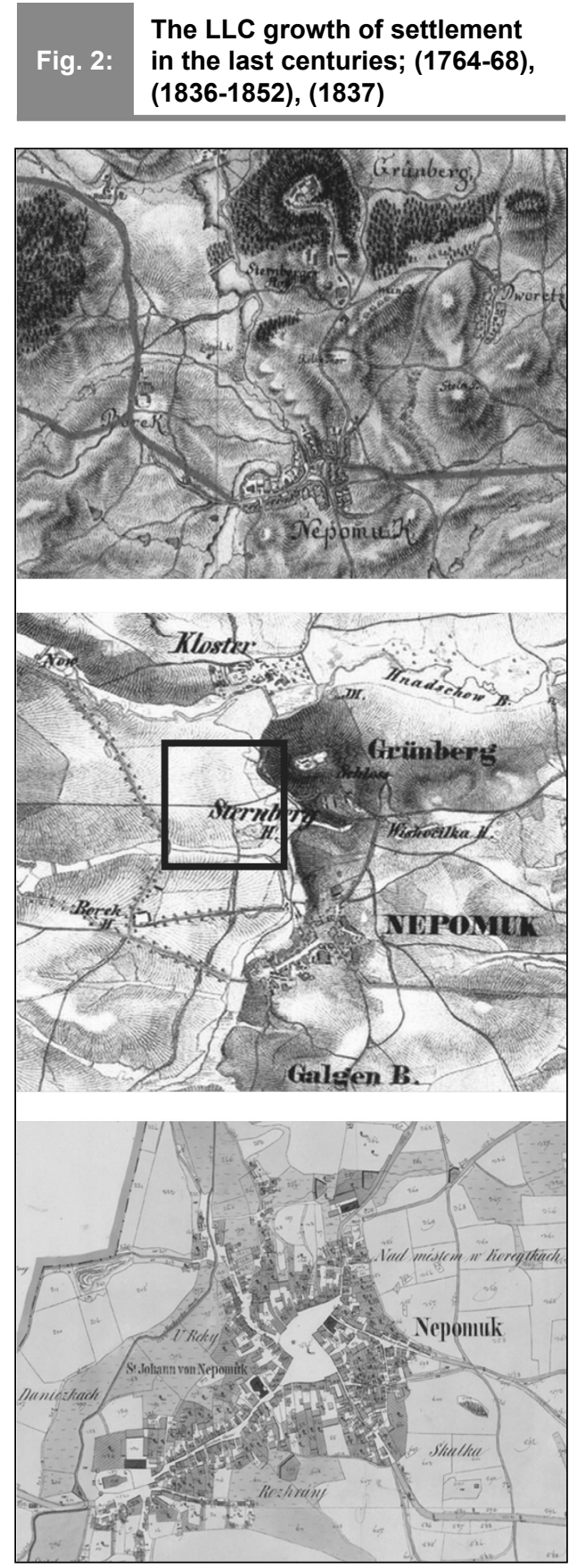

Source: Archives of Town Nepomuk conflicts between players and in 3D is expressed in the time, space and economy of the decision proposals. The presence of players in the right time at the right place is desirable. Proper functioning is to be ensured, for those who believe in the authorship of an invisible hand (Smith, 2013), through the implementation of self-regulation. On the other hand, there exists a culture of decision rules and their reflection on the planning: -territorial, -spatial and other dimensions (Sykora, Balchin, \& Bull, 1999). The simulation of a long-term development has a predominantly sophisticated support in professional simulation products. Metronamica is one of them, which has built-in allocation algorithms, that calculate the transition of cells (from one land use to another) on the basis of sophisticated rules (accessibility, zoning,...) (Stanilov \& Batty, 2011) or (Weber, 1929).

The purpose oriented software is in the main sophisticated and based on complicated generic formulas. This paper tries to pave the way to a rule oriented approach, based on the generally available software or applications directly created by the user.

\section{Rationale/approach to problem study: investment location}

The DM rules form the economic barriers and frames, as well as the character of the regional and urban or technical decisions space (Beran \& Dlask, 2005), (Batty, 2005), and (Weber, 1929). The decision rules create as well as establish probably one of the largest long-term regulations in a society taken as a whole. We understand the last sentence as a statement that creates benefits for a long-term conception. Payment for the economic deficiencies which result from the long-term fundamentals, acts for the whole lifetime period of construction works; for example, a tracing of roads, streets, railways, channels, housing structures etc. The given concepts, facts and their limits are mostly visible through centuries; see Fig. 2 . The main subject of interest of this paper is a DM mechanism and its impact on the regional economy. The problem is solved from another perspective - optimization in general, see in (Fotr, Plevný, Švecová, \& Vacík, 2013).

A development is limited not only by the life cycle (LC) of construction substances, but also by a long life cycle (LLC) of layouts, infrastructure etc. Among LLC construction objects are the transport infrastructure, 
engineering infrastructure, water distribution system and the usage of adjoining functional areas. This article aims to determine the potential benefits - thus the utility - of the use of the territory (area) $\omega$.

\section{Methodology: Simulation Model and Virtual Complexity}

The criterion for an economic development has to involve measuring the achieved utility in terms of relation (1) and is described in detail in chapter 2. Decision rules. The evaluation needs an aggregate prospect (prognosis) of the utility based on past investments in terms of sufficiency. The success of investment sets out a demarcation line of knowledge, infrastructure, industrial production, final consumption and housing, a broader view being given by (Damborský, Wokoun, \& Krejčová, 2013).

On the one side, interference in the general cycle

$$
\begin{aligned}
& \text { Consume } \Rightarrow \text { Investment } \Rightarrow \\
& \Rightarrow \text { Development } \Rightarrow \text { Consume }
\end{aligned}
$$

as a basic dependence is expressed in various forms in classical macroeconomics; it binds the investment $I$ with the change in production output $Y$ in time, written as

$$
I=v \mathrm{~d} Y / \mathrm{d} t
$$

where $0 \leq v \leq 1$, and shows the effectiveness of the proposed investment, $\mathrm{d} Y / \mathrm{d} t$ is change of production output for time unit $t$.

On the other side, (2) or (2a) doesn't solve the problem of the territorial distribution and the impact of decision-making rules. The choice and the suitability of the investment location is brought into play predominantly only through feasibility studies. Here we speak about the partial $l_{\text {solo }}$ investment and isolated micro-decisions. The further described simulation explains the potential benefits for the complexes: regions, areas. The study tries to explain, the extent to which (as \% of utility) the final effect might improve the efficiency of investment.

The authors of the paper argue that the DM rules implemented form the pattern of the future development. ADM rule directs the development of infrastructure, buildings and their potential economic destinations. The agricultural pattern of the area in Fig. 3 is changed to a more economically intensive exploitation. Decision rules orchestrate the evaluation. More about decision rules is presented in subsection of chapter 2.2 and in formulas (10), (11).

\subsection{Evaluation of Economic Potential - the Investment Tools and Indicators}

The regional development is recognized in the starting position $t$ mostly as an agricultural land without initial investment. Such an example presents a utility, prearranged in Fig. 2 and in segments $\omega_{i j}$ (see Fig. 3 ) weighted only with the weather volatility and the harvest incomes. We assume the location as a potential town expansion area, framed in Fig. 2. The proceeds or utilities $u_{i j}$ in the partial agricultural segments vary between 1 and $5 \%$ of yields per year.

Later, the initial investment (at time $t=1$ ) in the central located segment is written as $I_{t=1}(10,10)=1$ and will act as an initial spreading element for the development. The investment in a region (area) is fixed in time and localization, $I_{t}(i, j)$. The cumulated yields (utility) for a period $\left\langle t_{\text {start }}, \ldots, t_{\text {actual }}, \ldots, t_{\text {horizon }}\right\rangle$ is given as a aggregation (sum) of matrices $\boldsymbol{U}_{t}(\omega)=\sum_{t \text { start }}^{\text {tactual }} \boldsymbol{u}_{t}(\boldsymbol{\omega})$, where $\omega$ is the range of area (let us say for example, the territorial functions, the administrative definition etc.), and $t$ is an actual observer's time position. The single element $\omega_{i j}$ contains the value of simulated utility $u_{i j}$ of one period. The segment locations are specified with $i=1,2, \ldots, m$ and $j=1,2, \ldots, n$. To compare the different time stages, a number of indicators are available (e.g. difference, distance, divergence, etc.).

The difference of the stages $t$ and $t-1$ is given in general as a matrix of utility differences; indicated changes for $\Delta t$, given as a disparity matrix of the actual and past state

$$
\Delta \boldsymbol{u}_{t}(\omega)=\boldsymbol{u}_{t}(\omega)-\boldsymbol{u}_{t-1}(\omega)
$$

where data for matrices $\boldsymbol{u}_{t}(\omega), t=1,2, \ldots, t_{\text {actual }}$ is the confirmed reality or $t=t_{\text {start }}, \ldots t_{\text {actual }}$ is an accepted simulation on the basis of relations (10) and (11), visualized in Fig. 3, Fig. A1 or Fig. 7. An example of $\Delta \boldsymbol{u}_{t}(\omega), t=1,2, \ldots$ is given in Fig. 8. The matrices $\Delta \boldsymbol{u}_{t}(\omega)$ obtained in (3) are significant as an indication of the attractiveness of the potential $(t+1)$ investment.

The prediction of utility changes $\Delta \boldsymbol{u}_{t+1}(\omega)$, $\Delta \boldsymbol{u}_{t+2}(\omega), \ldots$ (where $t$ is interpreted as $t_{\text {actual }}$ ) can be derived by simulations, expert judgments, 
statistical analysis. The matrices $\Delta \boldsymbol{u}_{(t+x)}(\omega)$ allow calculation of further development states as

$$
\begin{aligned}
& \boldsymbol{U}_{t+1}(\omega)=\boldsymbol{u}_{t}(\omega)+\Delta \boldsymbol{u}_{t+1}(\omega), \\
& \boldsymbol{U}_{t+2}(\omega)=\boldsymbol{U}_{t+1}(\omega)+\Delta \boldsymbol{u}_{t+2}(\omega), \text { etc. }
\end{aligned}
$$

where the matrix $\boldsymbol{U}_{t}(\omega)$ is the sum of utilities for period $\left\langle t_{\text {start }}, t+1\right\rangle$, or even let us say a prognosis outlook from a last observer state $t_{\text {actual }}$ as a starting point for the prognosis. The matrix $\boldsymbol{u}_{1}(\omega)$ illustrates as $t_{\text {actual }}$ the "north-west" corner of Fig. 7 and matrix $\Delta \boldsymbol{u}_{t+1}(\omega)$ illustrates the "north-west" corner of Fig. 8.

The matrix $\boldsymbol{U}_{t}(\omega)$ multiplied by a vector of row relevancies (for example in terms of the urban, economic, social investment and development) $\mathbf{w}^{-}=\left[\mathrm{w}_{1}^{-}, \mathrm{w}_{2}^{-}, \ldots, \mathrm{w}_{\mathrm{k}}^{-}, \ldots, \mathrm{w}_{\mathrm{n}}^{-}\right]$where $0 \leq \mathrm{w}_{\mathrm{k}}^{-} \leq 1$ and $\sum_{k=1}^{n} w_{k}=1$ and by a vector of column relevancies $\mathbf{w}^{\prime}\left[w_{1}^{1}, w_{2}^{1}, \ldots, w_{l}^{1}, \ldots, w_{n}^{\mid}\right]^{T}$, where $0 \leq w_{l}^{l} \leq 1$ and $\sum_{l=1}^{m} \mathrm{w}_{l}^{l}=1$ identifies the main development trends. The matrices in (6) and (7) serve as development (change) indicators for the states $t$, written as row $(1 \times n)$ matrices $\boldsymbol{u}_{t}(\omega)$ for columns (read for example as a cumulated profile of west-east development)

$$
\boldsymbol{u}_{t}^{-}(\omega)=\mathbf{w}^{-} \boldsymbol{U}_{t}(\omega)
$$

and as columns matrix $(n \times 1)$ for rows (read for example as a profile of north-south development)

$$
\boldsymbol{u}_{t}^{\prime}(\omega)=\boldsymbol{U}_{t}(\omega) \mathbf{w}^{\prime}
$$

where $\mathbf{w}^{-}$is the row matrix of utility relevancies for columns of matrix $\boldsymbol{U}_{t}(\omega)$,

$\boldsymbol{u}_{t}^{-}(\omega)$ is the utility row matrix of sums for time phases $t=1,2, \ldots, t_{\text {actual }}$; let us say the west-east utility profiles of area $\omega$ up to the actual time horizon, example given in Fig. $4 b$,

$\mathbf{w}^{\prime}$ is column matrix of utility relevancies for rows $j=1, \ldots, m$ of matrix $\boldsymbol{U}_{t}(\omega)$,

$\boldsymbol{u}_{t}^{\dagger}(\boldsymbol{\omega})$ is the utility column matrix of weighted sums; in our example the north-south utility profile of area $\omega$ up to $t_{\text {actual }}$, example Fig. $4 a$.

The indicator of total yield of the investigated area $\omega$ can be given e.g. as matrix

$$
\boldsymbol{U}_{t}^{\circ}(\omega)=\mathbf{w}^{-} \boldsymbol{U}_{t}(\omega) \mathbf{w}^{\prime}
$$

More examples used later in this article are presented in Tab. 2.

The long-term economic profile is given by the simulation series $\boldsymbol{U}_{t}(\omega)$ and investment $I$ placement for all $t$ where $t_{\text {end }}$ is the used economic horizon $h$. The utility of investment (Beran \& Dlask, 2007) is not only a question of the effectiveness of sales, demand or offers, but also a question of the simulation inputs as

a) location,

b) the range of investment,

c) economic life cycle of investment,

d) reliability (risk) of economic activities in location,

e) potential growth factor in location, etc.

The above mentioned points should be interpreted with respect to the probabilistic causality in (Mitroff \& Silvers, 2013), mentioned in the Tab. 1 of our chapter Introduction. The utilities of an area $\omega$ is not only a sequence of cumulated utility matrices $\boldsymbol{u}_{1}(\omega), \boldsymbol{u}_{2}(\omega), \ldots$ but also the sophisticated calculation process of the partial combinatory parameters a) to e), implemented in a time sequence of simulations (to be read as delays or future expectations)

$$
\begin{aligned}
& \boldsymbol{U}(\boldsymbol{I}, \omega)=\operatorname{Sim}\left[\boldsymbol{u}_{1}(\boldsymbol{I}, \boldsymbol{\omega}), \boldsymbol{u}_{2}(\boldsymbol{I}, \omega), \ldots,\right. \\
& \left.\ldots, \boldsymbol{u}_{h}(\boldsymbol{I}, \omega)\right] \quad \text { for } t=1, \ldots, h
\end{aligned}
$$

where $\boldsymbol{U}(\boldsymbol{I}, \omega)$ is a time sequence of matrices of utilities for the area $\omega$, specified by investment conditions $I$ in uniform periods $t=1, \ldots, h$, etc.,

$I$ is the investment conditioned by a), ..,e),

$\boldsymbol{u}_{t}(\boldsymbol{I}, \boldsymbol{\omega})$ is the utility simulation for the time period $t$.

The economic potential establishes the base for the comparison of variants and preferences of different investment strategies. The long term effect is a significant DM indicator.

The comparison of variants may have a varied construction of indicators. The most affordable are indicators presented in relationship (3), (6) and (7).

\subsection{Decision Making Rules}

The DM criteria are mostly the rules of growth, providing a utility that oscillates with respect to the limiting local conditions, such as:

a) revenues, which are partially unstable and conforming to the external conditions (supply, demand, influence of externalities outside the territory of interest, energy prices, ecological regulation, tax regulations, charges etc.),

b) effect of investment time delay, if say the investment revenues are delayed for a few years, 
c) effect of revenue expands from an area element $\omega_{i j}$ to Moor neighborhood elements (eight), surrounding the calculated cell: pictogram as labeled later as $\omega^{\mathrm{M}}$,

d) total effect over longer time is dependent on both initial investment, and the level of randomness of the effects,

e) all effects (utility) are cumulated,

f) the decision making rule, applied to the time period $t$, influences area $\omega$ in time period $t+1$.

The authors of the paper argue that the DM rules implemented, form the pattern of the future development. A DM-rule directs the development of infrastructure and their potential economics. The agricultural pattern of the area in Fig. 3 is changed to a more economically intensive exploitation. Decision rules orchestrate the evaluation.

The evaluations enable a management decision about possible: a) state, b) changes, c) acceleration, d) volatility, etc. The example in Fig. 3 and in subsection chapter 2.3 presents the evaluation of a localization of the structural investments. The forthcoming periods (years) are evaluated (read that table processor elements $\omega_{x}$ are evaluated) by a decision rule given for instance as
IF (segment $\omega_{x}$ shows in previous time period growth, that it is higher than the given limit)

then yes $\Rightarrow$ increase in the actual time period by $\alpha \%$; no $\Rightarrow \mathbf{I F}$ (the surrounding of segment $\omega^{M}$ was growing in the previous period)

then yes $\Rightarrow$ random increase by a high (optimistic) assessment;

$$
\begin{aligned}
& \text { no } \Rightarrow \text { low random } \\
& \text { increase assessment)). }
\end{aligned}
$$

The relation (10) can be written in the form close to the table processor entry as

$$
\begin{aligned}
& \text { IF }\left(u_{t-1}\left(\omega_{x}\right) \geq I \cdot\right. \text { index of required growth } \\
& \text { then } u_{t}\left(\omega_{x}\right)=u_{t-1}\left(\omega_{x}\right) \cdot \text { index of required } \\
& \text { growth } \bullet R_{1} \\
& \text { or else IF (surrounding } \left.u_{t-1}\left(\omega_{x}{ }^{M}\right) \geq I\right) \\
& \text { then } u_{t-1}\left(\omega_{x}{ }^{M}\right) \cdot R_{2} ; \\
& \text { or else } \left.u_{t-1}\left(\omega_{x}{ }^{M}\right) \cdot R_{3}\right)
\end{aligned}
$$

where $\mathrm{R}$ is the random-number generator with required probability density distributions $\mathrm{R}_{1}, \mathrm{R}_{2}, \mathrm{R}_{3}$,

$I$ is initial investment implemented into area, $\omega_{x}$ is particular element $x$ of area $\omega$,

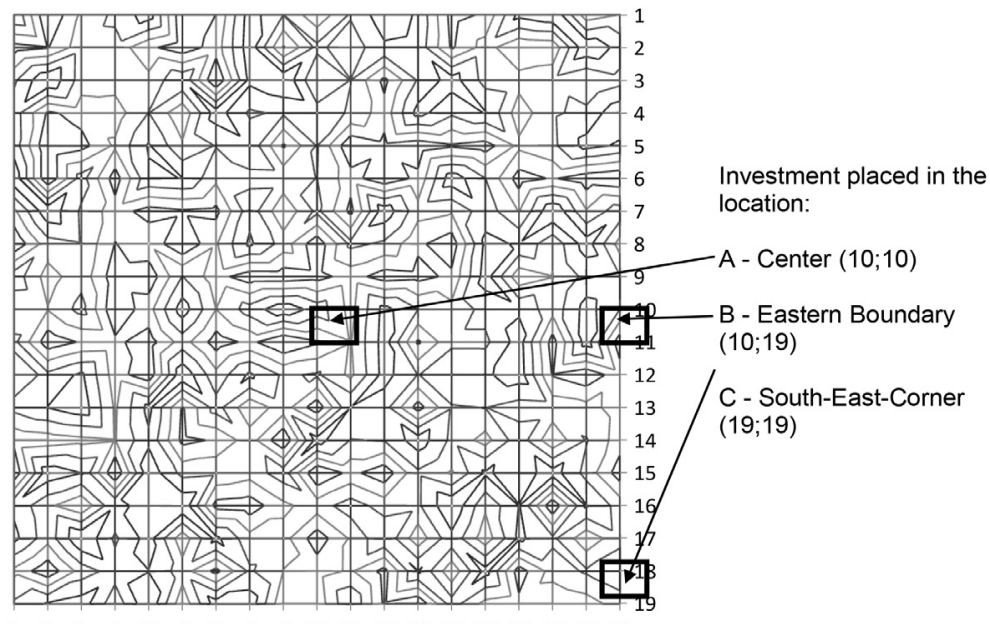

$\begin{array}{lllllllllllllllllll}1 & 2 & 3 & 4 & 5 & 6 & 7 & 8 & 9 & 10 & 11 & 12 & 13 & 14 & 15 & 16 & 17 & 18 & 19\end{array}$ 
$\omega_{x}{ }^{M}$ is Moore neighborhood of the element $x$; surrounded by 8 elements,

index of growth is calculated as $e^{\alpha t}$ where $\alpha$ is an expected growth factor.

To simplify interpretation, we assume that the infrastructure is starting on agricultural land (without revitalization, land reclamation, environmental restoration, etc.). Any investment creates the effects in $t$, according to the rules, mentioned before in a) to e); the effects are dispersed and calculated according to (10) and (11).

\subsection{Meta-Analysis}

The described approach can be interpreted and generalized to a large range of development situations, and the precision and accuracy of the calculation can be improved if a denser grid is used. More realistic information may increase the detected interpretation effects. For the protection of property rights in the most practical examples, we use further for our illustration a metadata simulation, based on the historical locality specified in Fig. 2.

\subsection{Location of Investment - Comparison}

The location of investment $\boldsymbol{I}$ in area $\omega$ is an important economic step that creates a utility $u_{t}\left(\omega_{i j}\right)$ for the particular investment in period $t$. Afeasibility study of an individual solo investment, without respect to the spread (read as impact) on the $\omega$, does not enable description of the long term utility effects. More about the evaluation and localization of an area is written in (Zang, 2012; Žižka, 2010). The category includes the location indicators, quotients, shift-share analysis, the Gini coefficient of localization, the Ellison, Glaeser agglomeration index etc. The economic impact of the location will be visible if we change the investment location; the initial investment locations are in center " $A$ " and then in the site boundary " $\mathrm{B}$ ", and in the south-east corner of the area described as "C", see Fig. 3. Experimental results as the sum of utilities is written as $\boldsymbol{U}_{t}(\omega)$, and are presented in Tab. 2 .

The simulated sum of utilities $\boldsymbol{U}_{t}(\omega)$ for location of $\boldsymbol{I}$ in $\omega$-areas A, B, C for the intended investment in Fig. 2, illustrate the expected benefits. The ranges of $\min$ and max differs.

\begin{tabular}{|c|c|c|c|c|c|}
\hline $\begin{array}{l}\text { Simulation res } \\
\text { ness } \alpha=1.05 p\end{array}$ & & $\begin{array}{l}\text { ent } I=1 \\
\geq I \text { with }\end{array}$ & $\begin{array}{l}\text { d in A, ol } \\
\text { ility } 10 \% \text {; }\end{array}$ & $\begin{array}{l}\text { nd C; exp } \\
J_{t}(\omega) \leq I \text { is }\end{array}$ & $\begin{array}{l}\text { ed effective- } \\
\text { atility } 5 \%\end{array}$ \\
\hline Location $I=1$ for areas & & $\min$ Sum & max Sum & Expected & Dispersion $\sigma$ \\
\hline Center $(10,10)$ & A & 178.38 & 420.19 & 322.70 & 48.96 \\
\hline Eastern boundary $(10,19)$ & B & 207.08 & 426.85 & 306.47 & 44.38 \\
\hline South East corner $(19,19)$ & $\mathrm{C}$ & 185.10 & 375.12 & 298.03 & 40.90 \\
\hline Area utility for agriculture & $\mathrm{D}$ & 112.61 & 354.98 & 253.18 & 47.89 \\
\hline
\end{tabular}

Note: 1. Dispersion is given as standard deviation $\sigma=\sqrt[2]{E\left[(X-\mu)^{2}\right]}, E[X]=\mu$

Source: own

2. See relations to (Tab. 2). in (Fig. 3).

The differences between the max and the min utility $\boldsymbol{U}_{t=10}(\omega)$ are high. In practical applications the technical conditions are sophisticated, and the situation speaks even more strongly for the use of the advanced quantification methods. These offer the application of the optimization techniques in (Fotr, Plevný, Švecová, \& Vacík, 2013) which "...aims to specify the problem of optimization of development of a project portfolio under risk (optimal allocation of scarce resources)". In Appendix there is a visualized situation with some limits of growth. The restrictions create investment limits (river, transit-road, eco-corridor, parks, and forest) and change the potential spread of development, see Appendix Fig. A1. For simplicity, the optimization was not applied. However, the simulations of the utility parameters are the necessary basis for formulation of the objectives and optimization function.

Actually:

1. the territory development is caused by random variations of market conditions in a determined region, 
2. from the middle term view, development in a territory is influenced by all the urbanization phases from the past,

3. the highest development in a territory (Fig. A1) doesn't have to appear only in the initial segment, chosen for the investment (see dispersion effect in Fig. 4a, b),

4. shift in the segments with the highest custom (utility) effect in the area change the proportion according to the time of influence.

The results and properties of a real urban simulation can be described in the form of analysis and particular simulations for $t=1, t=2, \ldots$, and can provide answers to the questions:

a) to what extent is it rational to assume that the territorial development is unique?

b) to what extent is the final initiating effect of the starting investment unique?

c) what are the criteria expedient for investment in the urbanized district?

Each territory is a singular entity. Questions in this category can be answered only by a simulation. Appendix interprets in Fig. A1 the simulated benefits in the area with restrictions (limits), and the infrastructure investments are placed and start from the South-East corner. The simulated area includes limits, such as a small water flow or a road. Both limits represent obstacles to additional investment requirements, bridges, and auxiliary communications. The development profiles are visible in Fig. $4 \mathrm{a}$, and $4 \mathrm{~b}$ as cumulative values in $\boldsymbol{U}_{t=1, \ldots, 10}(\boldsymbol{\omega})$ and $\boldsymbol{U}_{t=1, \ldots, 10}(\boldsymbol{\omega})$. The approach allows an economic comparison of changes, encouraging the creation of new designated components and their limits.

\subsection{Evaluation of Investment Location - Dispersion Model}

The development area has its cumulative utility $\boldsymbol{U}_{t}(\omega)$ profile. The simulation opens out to better insight into potentials for future development.

The economic criterion of Payback Period is a short term indicator (to reach a recoup of the capital expended in an investment, or to reach the break-event point). In the simulation example as presented in Fig. $4 a, b$ the time unit is 5 or 10 years and the dimension of the time horizon is about 50 or 100 years. The evaluation is based on expression (6) and (7). We assume that the calculation has to be realized for every single territory segment $\omega_{i j}$.
A commercially focused management aims for the short-term effects and paybacks. In most cases the use of such strategies is practiced due to the lack of information about the dynamics in time and the risk of investment. A more sophisticated economic understanding (DM) has to respect the reality of a long-term economy and the risk involved in the long life cycle of a substantive investment. The transfer from the extensively used areas, for example agriculture seen in Fig. 3, and a revitalization towards the intensively used ones (services, industry, housing, seen Fig. A1 constitute the potential for regional management. Commercial investors tend to respect in their development projects a relatively short time horizon (early repayment of credit). A public administration should look for effectiveness in the full lifecycle as $\max \boldsymbol{U}_{L C}(\boldsymbol{\omega})$. The calculation tool is appropriate for such problems in simulation.

Fig. $4 a, b$ shows the benefits of each particular investment location and the impact on the surrounding area. Volatility in the growth of individual area segments is caused by natural relief conditions (river, road, bridges, forest, existing residential development, etc.), see Appendix Fig. A1.

The schematic aggregated development, respecting restriction on the development is given in Tab. 3. In Fig. 5 there is presented a simulation of investment located in the center of $\boldsymbol{\omega}$. The differences in data are illustrated in Fig. 4a and Fig. 4b, and are very cautionary. The transaction costs for an ad-hoc investment location are over the life-cycle very high and indicate the price for missed economic opportunities. Fig. 6 implements Tab. 3 data into a graphic sequence. The profound consequences of a wrong localization of an initial investment are visible at the end of the life cycle. They extend in our simulation to many times the value of the initial investment.

\section{Research Results}

The simulation of an RD area involves a number of situations along with a more individual view connected with the particular project, as is mentioned above. An interesting global view exists. The total and partial development revenues of disposable territory segments $\omega_{i j}$ were mentioned in subchapter 2.1 with the expressions given in (3), (4), and (5).

The indication of main streams of utility is indicated by $\boldsymbol{u}_{t}^{-}(\omega)$ and $\boldsymbol{u}_{t}^{\perp}(\omega)$ in expressions 
Utilities $U_{t}^{-}(\omega)$ and $U_{t}^{\prime}(\omega)$ spread profiles for $t_{1}, \ldots, t_{10}$ as initial investment is in position C - South-East area corner $\left(I_{19,19}\right)$ before and after crossing river and road
a) matrices $U$
b) matrices $U_{t=1}$
$(\omega)$ presents simulation of North-South cumulative values,
(w) presents West-East cumulative values
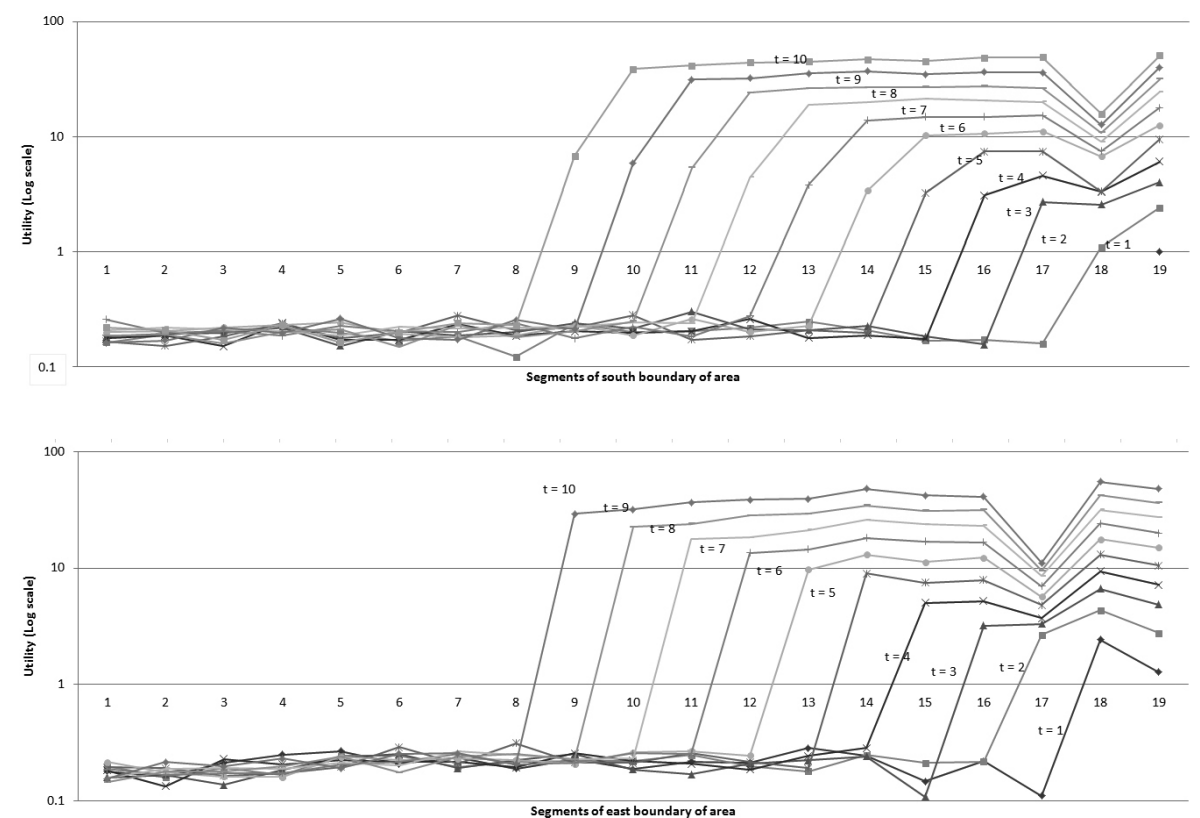

Source: own

(6) and (7). The practical situation illustrates Fig. 4a, b and Fig. 5; we may speak about the states in $t=1, \ldots, h$. Interesting for the direction of a new investment are also $\Delta \boldsymbol{U}_{t}^{-}(\omega)$ and $\Delta \boldsymbol{u}_{t}^{\text {! }}$ $(\omega)$. They indicate the direction of changes for $t=1, \ldots, h$.

We are looking for the answer to the posed question, in what direction (time, space, economics) the territory development has to be managed.

Development of a land-use plan is a factual instruction as to the direction in which future development has to go, and what constituent parts of the territory have to be used. Instruments for the complicated decision-making entailed are very few and they are mostly based solely on the long-term experience of development in the given territory.

Urbanization, as it is known today in contemporary regions and cities, is a result of development over several centuries, see changes from agriculture in Fig. 2 or development sequences $t=1, \ldots, 8$ in Fig. 7 .

The past development was several times slower than development at the present time. It is no exaggeration to say (at least in industrially exposed regions) that the rates of the growth of a territory burden from the viewpoint of population level, the growth of industrial production (for example GDP per territorial unit $\left[\mathrm{km}^{2}\right]$, see Fig. 1), are beyond any historical comparison.

A comparison which shows that the present generation consumes the same quantity of resources and industrial assets as all previous generations is both limiting and alarming. Important details are concentrated in the sonamed Stern Report (Stern, 2006).

Professor Stern lists the basic economic and ecological arguments that can actuate and 


\section{Ekonomie}

\section{Fig. 5: Vectors $U_{t}\left(\omega_{i j}\right)$ for $t_{1}, \ldots, t_{10}$; the initial investment in $\omega$ location: A - Center}

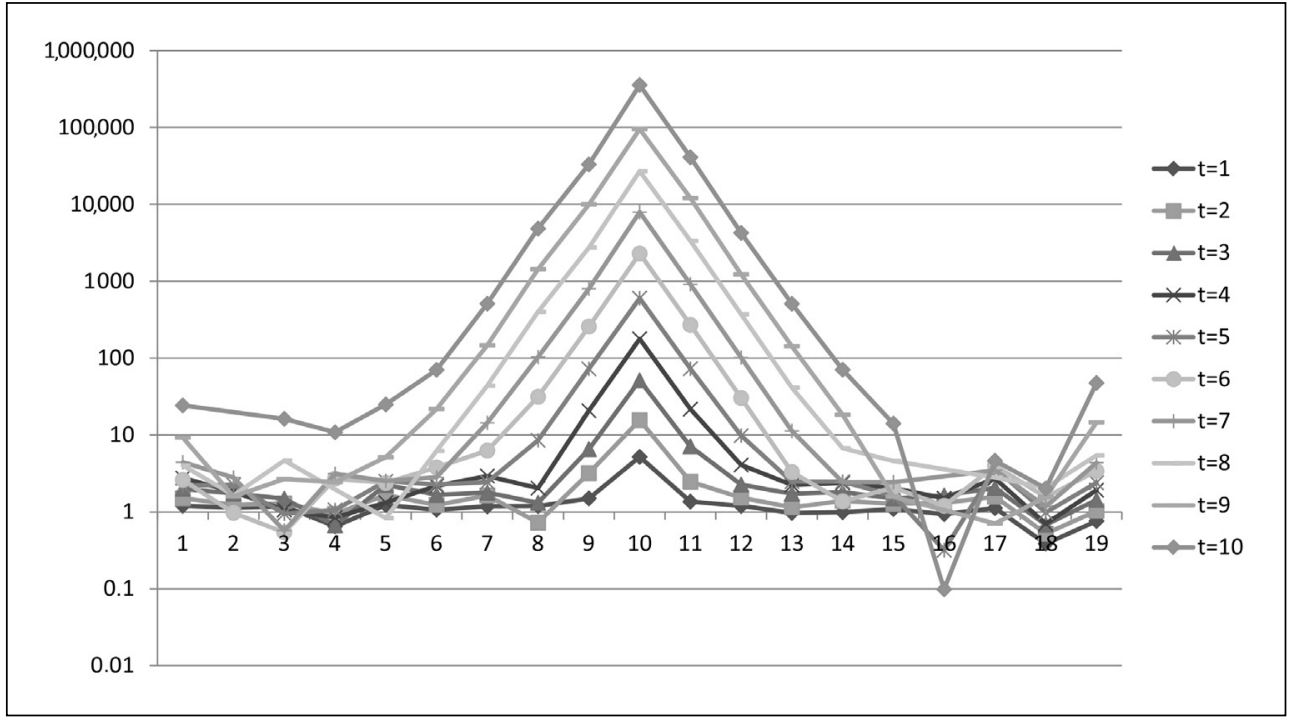

Source: own

Tab. 3:

Time sequence of simulations of $I=1$ localized in A, or B, and C; growth effectiveness 1.03; restriction on development are shown in Appendix Fig. A1

\begin{tabular}{l|c|c|c|c|c|c|c|c|c|c}
\multicolumn{1}{c|}{ Utility It } & $\mathbf{1}$ & $\mathbf{2}$ & $\mathbf{3}$ & $\mathbf{4}$ & $\mathbf{5}$ & $\mathbf{6}$ & $\mathbf{7}$ & $\mathbf{8}$ & $\mathbf{9}$ & $\mathbf{1 0}$ \\
\hline A-Center (10,10) & 19 & 19 & 23 & 32 & 51 & 97 & 174 & 587 & 2,693 & 16,742 \\
\hline B - Eastern boundary $(10,19)$ & 19 & 19 & 23 & 28 & 38 & 53 & 80 & 136 & 363 & 1,489 \\
\hline C-South East corner (19,19) & 20 & 20 & 25 & 35 & 48 & 77 & 155 & 310 & 1,325 & 6,748 \\
\hline Agriculture & 17 & 18 & 22 & 27 & 36 & 47 & 65 & 95 & 171 & 495 \\
\hline
\end{tabular}

also factually prove the mentioned statements. The concept, which was observable, represents a further attempt to explain the long-term behavior of territorial units in a situation when a rapid development of industrial consumption and services requires fast and competent decision-making. The creation of an instrument for investment localization is a necessity. For this complicated task there are limited SW and calculation methods available.

The proposed approach is an instrument, and an opportunity to apply simulation to the explanation of territorial and regional behavior within time and space. The paper concerns a quantification of differences between the separate functional segments of the territory.
Every single territorial segment, read as $\omega_{i j}$ is evaluated and serves towards an intermediate decision in the moment of time $t$. Moreover, it has its own autonomous component of a strategy of growth within time. In the relations (10) and (11), the notion of $\omega_{x}^{M}$ surrounding is used for the choice of expansion direction. The simulation algorithm assumes that the matter concerns the development only when the two territorial components $\omega_{i j}$ have a common border.

\section{Conclusion}

Ahistorical perspective (expressed as time series statistics) in present day modern economics does not have a decisive influence. A prognostic 


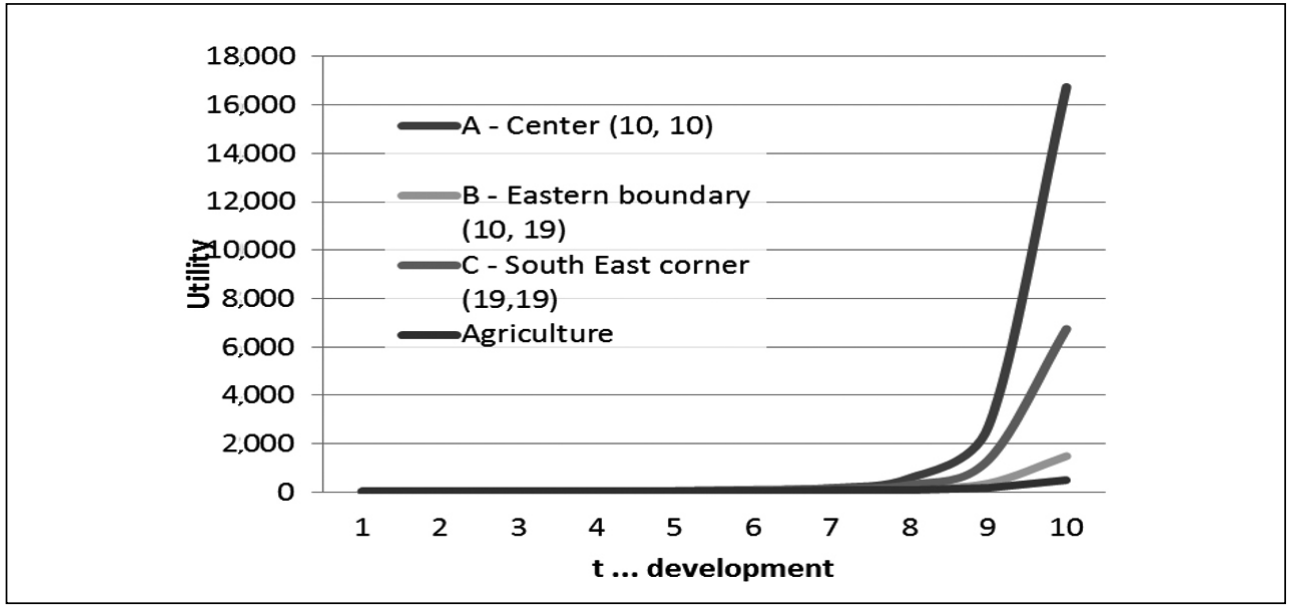

Source: own

calculation in the form of a continuation of time series should not and mostly does not have any causal dependence for new (efficient) decisions. New ideas and new approaches are desired, as seen in Appendix Fig. A2. In classical economics there are discussed only three basic factors of production: land, labor, capital. Contemporary economists consider entrepreneurship (meaning management) as a factor of production. The article points to the contribution of public capital in development and its lack of appreciation in microeconomics. In macroeconomics there is work in progress and extensive discussion (in EU, US, and elsewhere) based on arguments summarized (2014) in the book Capital in the Twenty-First Century by Prof. Thomas Piketty (Piketty, 2014). Macroeconomics deal mainly with fiscal instruments. Microeconomics focuses on price and benefit. The path between the simplification referred to in (2a) and a revision of public investment in the area is a challenging task. As is taxing very high incomes at 60 or $80 \%$ at macroeconomic level.

Returning to the current simulation example and to relevant results we see:

1. the simulation rules in terms of (11) form the long term growth of local utilities in time; see Fig. 7.

2. In terms of volatility of $R_{1}, R_{2}$ and $R_{3}$ there are presented the benefit strengths. The overall growth pattern (dispersion from $\omega_{10,10}$, A-Center) is unaffected; the overall effect shows a continuous growth, see Fig. 7 and Tab. 3.

3. The growth rate (intensity, differences) is changing over time, see Fig. 8. Moreover, the growth rate is

a) moving in time,

b) the effect (power) of the initiating investment over time loses intensity,

c) the initiating investment brings profit adjacent to the neighborhood; the advantage of initial investment is timelimited, (in Fig. 8 till $t_{4}$ or $t_{5}$ ),

d) predominant effects are seen growing outside the primarily initiating $\omega_{10,10}$ investment area.

The relation of the simulation and territorial development can offer new broader views; complementary to investment efficiency and rate of return, indicated in the context of (1). The new approach may confirm or disprove the investment decisions. The long-term effects are mostly beyond the economic horizon of current practice. Particularly the GIS data enable a more sophisticated simulation of fitting together the effect within the bounds of landuse planning and investment decisions, on which there is more in (Henderson, 1986).

A response to efficiency in the form of calculations of investment intensity is certainly 


\section{Ekonomie}

Fig. 7:

Simulations $U_{t}(\omega)$ of utility from territorial development in time sequence after initial investment in $\omega_{10,10}$; utility accumulation in time (from left to right top-down $t_{1}, t_{2}, \ldots, t_{7}, t_{8}$ )
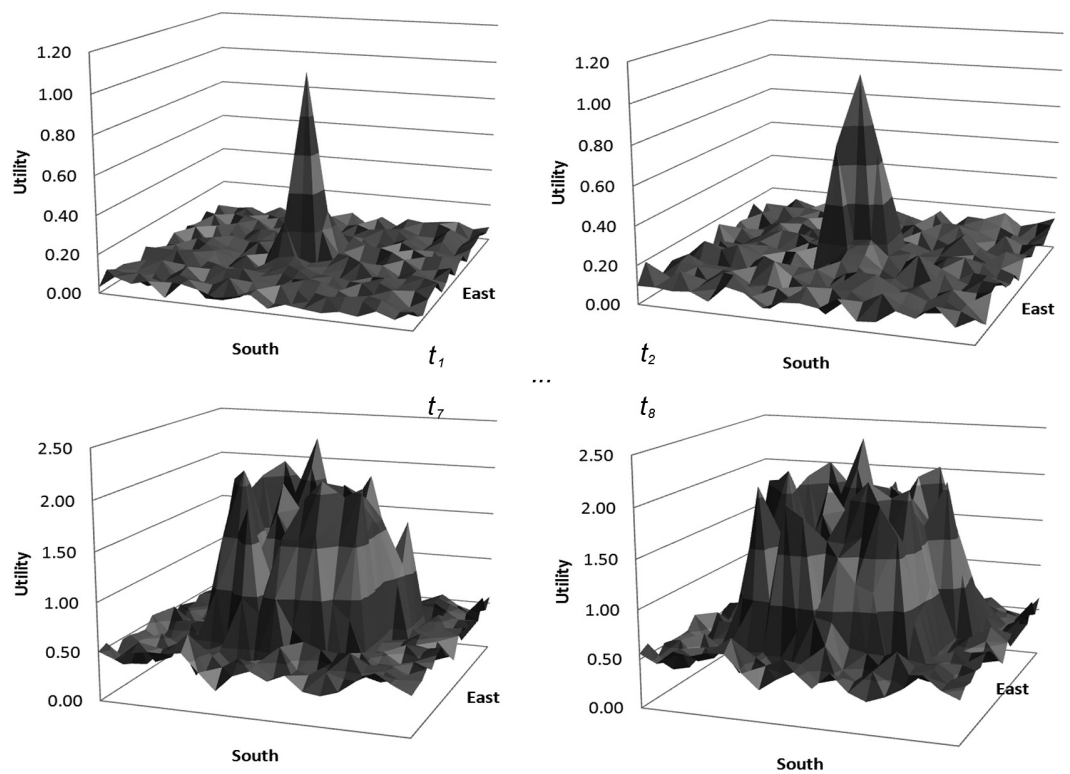

Source: own

Differences $\Delta u_{t}(\omega)=u_{t}(\omega)-u_{t-1}(\omega)$ according to (3) in territory growth for investment in $\omega_{10,10}$ in time, time development (from left to right top-down, $t_{1}, t_{2}, \ldots, t_{7}, t_{8}$ )
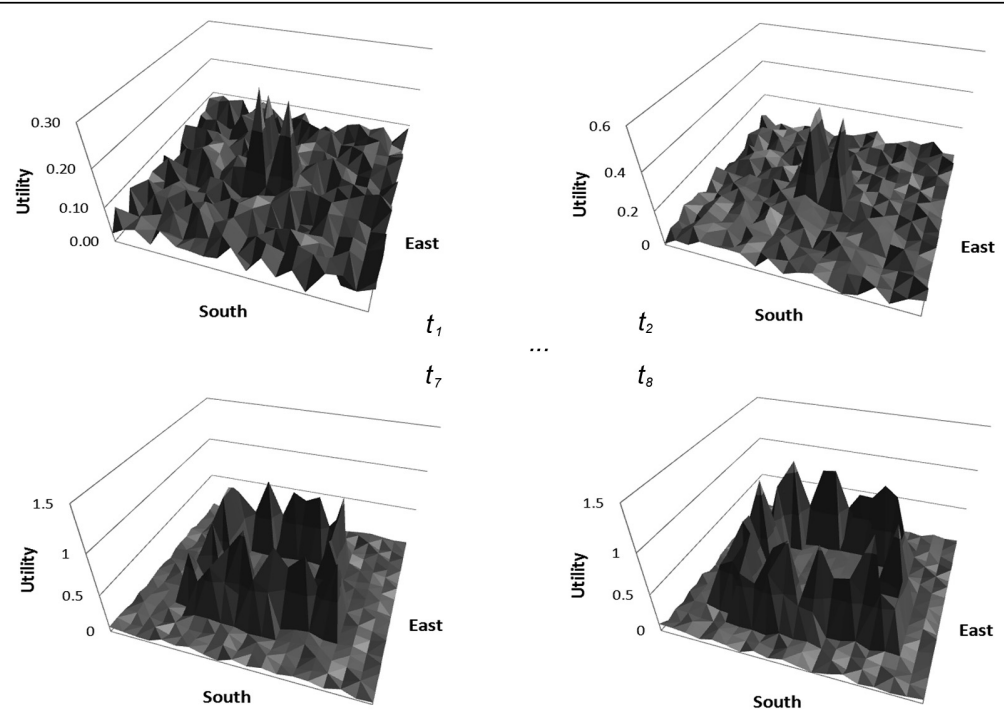

Source: own 
a good financial economic tool. In any case, it builds up to a new view on the issue of investment and the use of limited resources. On the other hand, the approach does concentrate on the interest of a decision maker in the longterm life-cycle of the territory.

By means of the simulation of development trends, intermediate segments in a territory (that is area, region, and district) can be found that demonstrate the highest added value. In many cases, unfortunately, there is a danger that any situation will be dealt with or solved before full recognition or understanding.

This paper originated as part of research project TAČR TD020040 „TD020040 Tools for the Support of Technical-economic Activities", financed by the Technology Agency of the Czech Republic.

\section{References}

Artis, M., Curran, D., \& Sensier, M. (2010). Investigating Agglomeration Economies in a panel of European Cities and Regions. Manchester: ESPON \& University of Manchester.

Batty, M. (2005). Agents, cells, and cities: new representational models for simulating multiscale urban dynamics. Environment \& Planning, 37(8), pp. 1373-1394. doi:10.1068/ a3784.

Beran, V., \& Dlask, P. (2005). Management of sustainable development of regions, settlements and villages (1st ed.). Prague: Academia.

Beran, V., \& Dlask, P. (2007). Risk as an externality in quantitative and marginal approaches. In W. Heijman, Regional Externalities (pp. 255-286). Berlin: Springer Berlin Heidelberg.

Beran, V., \& Dlask, P. (2011). Mapping of synchronous activities through virtual management momentum simulation. Construction Innovation, 11(2), pp. 190-211.

Damborský, M., Wokoun, R., \& Krejčová, N. (2013). The Effectiveness of Industrial Zones Support in the Czech Republic. E\&M Ekonomie a Management, 16(4), pp. 104-117.

Dixon, T., Eames, M., Hunt, M., \& Lannon, S. (2014). Urban retrofitting: Mapping the transition to sustainability by 2050. Abingdon: Routledge.

European Commission. (2013). Quality of life in cities - Perception survey in 79 European cities: Flash Eurobarometer 366. Luxembourg: Publications Office of the European Union.

Forrester, J. (1961). Industrial Dynamics. Leverage Networks, Acton.

Forrester, J. (1969). Urban Dynamics. Leverage Networks, Acton.

Fotr, J., Plevný, M., Švecová, L., \& Vacík, E. (2013). Multi-Criteria Project Portfolio Optimization under Risk and Specific Limitations. E\&M Ekonomie a Management, 16(4), pp. 70-88.

Gallegati, M., Keen, S., Lux, T., \& Ormerod, P. (2006). Worrying trends in econophysics. Physica A: Statistical Mechanics and its Applications, 370(1), pp. 1-6. doi:10.1016/j. physa.2006.04.029.

Henderson, J. (1986). The Efficiency of Resources Usage and City Size. Journal of Urban Economics, 19(1), pp. 47-70. doi:10.1016/0094-1190(86)90030-6.

Lennert, M., \& Robert, J. (2010). The territorial futures of Europe: 'Trends', 'Competition' or 'Cohesion'. Futures, 42(8), pp. 883-845. doi:10.1016/j.futures.2010.04.013.

Malecki, E. (2012). Regional Social Capital: Why it Matters. Regional Studies, 46(8), pp. 11021103. doi:10.1080/00343404.2011.607806.

Mandelbrot, B. (1991). Die Fraktale Geometrie der Natur. Basel - Boston - Berlin: Birkhäuser Verlag. doi:10.1007/978-3-03485027-8.

Mitroff, I., \& Silvers, A. (2013). Probabilistic causality. Technological Forecasting and Social Change, 80(8), pp. 1629-1634. doi:10.1016/j. techfore.2013.02.009.

Mitsova, D., Shuster, W., \& Wang, X. (2011). A cellular automata model of land cover change to integrate urban growth with open space conservation. Landscape and Urban Planning, 99(2), pp. 141-153. doi:10.1016/j. landurbplan.2010.10.001.

Parker, D. (2007). Revealing spatial externalities: Edge-effect externalities and spatial incentives. Journal of Environmental Economics and Management, 54(1), pp. 84-89. doi:10.1016/j.jeem.2006.12.004.

Piketty, T. (2014). Capital in the TwentyFirst Century. Harvard University Press.

Prunetti, D., Muzy, A., \& Innocenti, E. (2014). Multi-agent System with Spatial Interactions: The Case of Virtual Estate Development A Stochastic Simulation-based Modeling Approach. Computational Economics, 43(3), pp. 271-299. doi:10.1007/s10614-013-9372-0. 


\section{Ekonomie}

Smith, A. (2013). Project Gutenberg. An Inquiry into Nature and Cause of the Wealth of Nations. Retrieved from https://www.gutenberg. org/files/3300/3300-h/3300-h.htm.

Stanilov, A., \& Batty, M. (2011). Exploring the Historical Determinants of Urban Growth Patterns through Cellular Automata. Transactions in GIS, 15(3), pp. 253-271. doi:10.1111/j.1467-9671.2011.01254.x.

Stern, N. (2006). The Economics of Climate Change. Retrieved from: www.sternreview.org. uk.

Stimson, R., Stough, R., \& Brian, H. (2006). Regional Economic Development: Analysis and Planning Strategy. Berlin: Springer-Verlag. doi:10.1007/3-540-34829-8.

Sykora, L., Balchin, P., \& Bull, G. (1999). Regional Policy and Planning in Europe. New York: Routledge.

Tao, Y., Tang, G., \& Strobl, J. (2012). Spatial structure characteristics detecting of landform based on improved 3D Lacunarity model. Chinese Geographical Science, 22(1), pp. 8896. doi:10.1007/s11769-012-0516-2.

Weber, A. (1929). Theory of Location of Industries (1st ed.). Chicago: University of Chicago Press. doi:10.1111/j.1467-9957.1937. tb01400.x.
Wolfram, S. (2002). A New Kind of Science. Wolfram Media.

Zang, W. (2012). An Economic Theory of Cities: Spatial Models with Capital, Knowledge, and Structures. New York: Springer Science \& Business Media. doi:10.1007/978-3-642-56060-6.

Žižka, M. (2010). Methods for identifying clusters. Proceedings of 28th International Conference on Mathematical Methods in Economics 2010 (pp. 700-705). České Budějovice: University of South Bohemia in České Budějovice.

doc. Ing. Václav Beran, DrSc. Czech Technical University in Prague Faculty of Civil Engineering Department of Economics and Management University of South Bohemia in České Budějovice Faculty of Economics beran@fsv.cvut.cz

doc. Ing. Petr Dlask, Ph.D. Czech Technical University in Prague Faculty of Civil Engineering Department of Economics and Management dlask@fsv.cvut.cz 

east corner $(19,19)$. Restrictions: east vertical is river, south horizontal is road.

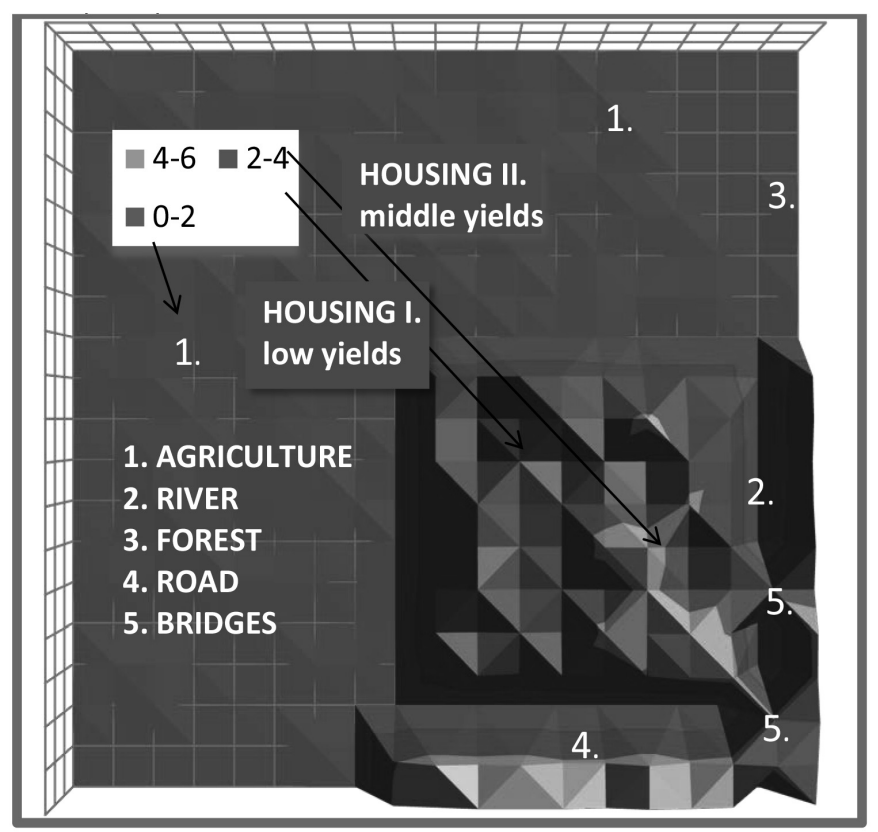

Source: own

Published items and citations (from 1995 to January 2014) for topic chain: urban development and cellular methodology
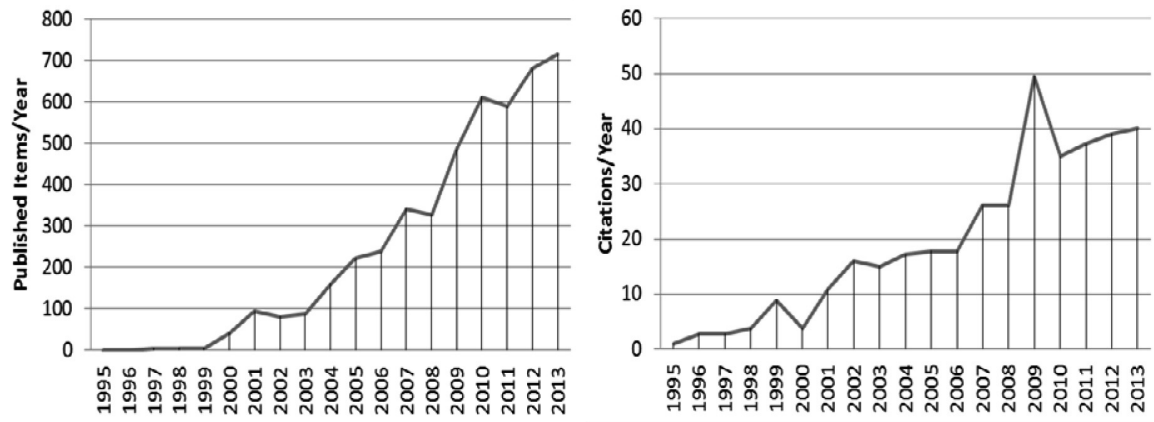

Source: own based on Database ISI 


\section{Abstract}

\section{LONG-TERM INFRASTRUCTURE INVESTMENT: A NEW APPROACH TOTHE ECONOMICS OF LOCATION}

\section{Petr Dlask, Václav Beran}

Contemporary modern development of a region $(R D)$ is associated with some conception of economic volatility and technological knowledge. The $R D$ is triggered by the existence of an infrastructure as a threshold. Only then can we expect the long-term economic and regional effects. From the long-term view, the development of most regions is also associated with a surprising diversity. The reasons for growth or stagnation are very often indistinct, and in some cases they are even unidentifiable.

Existing development is a materialized foot print of earlier economic activities and there is more about that, for example, in Quality of life in cities, (European Commission, 2013). We should understand the economics of RD as an account; an account of either poor or successful regional management. In other words, regional economics and management (E\&M) is at its causal roots a proof of the right or wrong decision rules and their implementation. This article argues that the state of municipalities and of regions is only partly a hostage of the regional investment economy and that a non-negligible way to success is paved by decision making processes especially through the use of certain decision criteria.

The paper aims to demonstrate that:

a) an elementary decision rule determines the decision space determining both time and conceivable actions, (timing of innovations, use and functions of areas, implementation of particular investments, localization of research directions, market expansion, etc.);

b) dispersion effects are around and outside the primary investment that generates the growth;

c) the burnout effect of the initial investment exists and begins to act after a certain time period;

d) fixing the time of the initial investment burnout is identifiable and can be calculated.

Point c) and d) represent triggers for any need of new investments, usually called innovation, modernization, reconstruction etc.

Key Words: Development, utility, simulation, infrastructure, evaluation, metamodel.

JEL Classification: C63, C81, 018, R58.

DOI: 10.15240/tul/001/2016-3-004 